\title{
SENSORY INFLUENCES ON SALT, SUGAR AND FAT INTAKE
}

\author{
R. SHEPHERD \\ AFRC Institute of Food Research, Norwich Laboratory, Colney Lane, \\ Norwich NR4 7UA
}

\section{CONTENTS}

INTRODUCTION . . . . . . . . . . . . . . . . . . 125

INFLUENCES ON FOOD CHOICE AND INTAKE . . . . . . . 125

RELATIVE IMPORTANCE OF SENSORY ATTRIBUTES IN DETERMIN-

ING FOOD CHOICE . . . . . . . . . . . . . . . . . 127

TYPES OF SENSORY MEASURES . . . . . . . . . . . . . . . $\quad$. 128

RELATING SENSORY MEASURES TO INTAKE . . . . . . . . 129

SALT . . . . . . . . . . . . . . . . . . . . . . 129

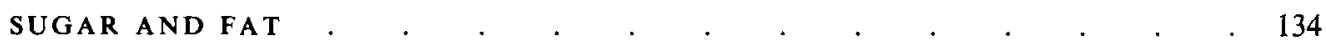

DIETARY MANIPULATIONS . . . . . . . . . . . . . . . . . 136

EFFECTS OF DISEASES ON SENSORY RESPONSES. . . . . . . . . . 138

CONCLUSIONS

REFERENCES . . . . . . . . . . . . . . . . . . . .

\section{INTRODUCTION}

The sensory attributes of foods are widely considered to have an important role in influencing intake of particular foods (Booth et al. 1976; Cabanac, 1979; Fantino, 1984). Thus they should have an important impact on the nutrient intake of people.

In the present paper the role of sensory factors in influencing food selection and hence nutrient intake will be discussed. First a general overview of the types of factors determining food selection will be presented. This will be followed by a brief description of how sensory measures of sensitivity and preference are defined. Specific examples of the relationship between taste variables and intake of salt, sugar and fat will be considered, along with the effects of variations in the diet on sensory measures. The influence of disorders of taste and disease on intake will then be discussed.

\section{INFLUENCES ON FOOD CHOICE AND INTAKE}

It is important to distinguish between choice between different types of foods and choice between different examples of the same type of food (e.g. different brands of a processed food or different varieties of fresh vegetable). In general nutrient intake is affected by the first type of choice much more than the second. Thus consumption of an apple rather than cheese after a meal will have a large impact on nutrient intake, whereas choice of one variety of apple rather than another will have little effect on nutrient intake. The first type of choice will have a wide variety of influences of which sensory preference may be one, whereas in the latter case the sensory aspects may be of more importance.

Selection of particular foods from a range available will be influenced by a large number of different kinds of factors, not only the sensory attributes of the foods. There have been 


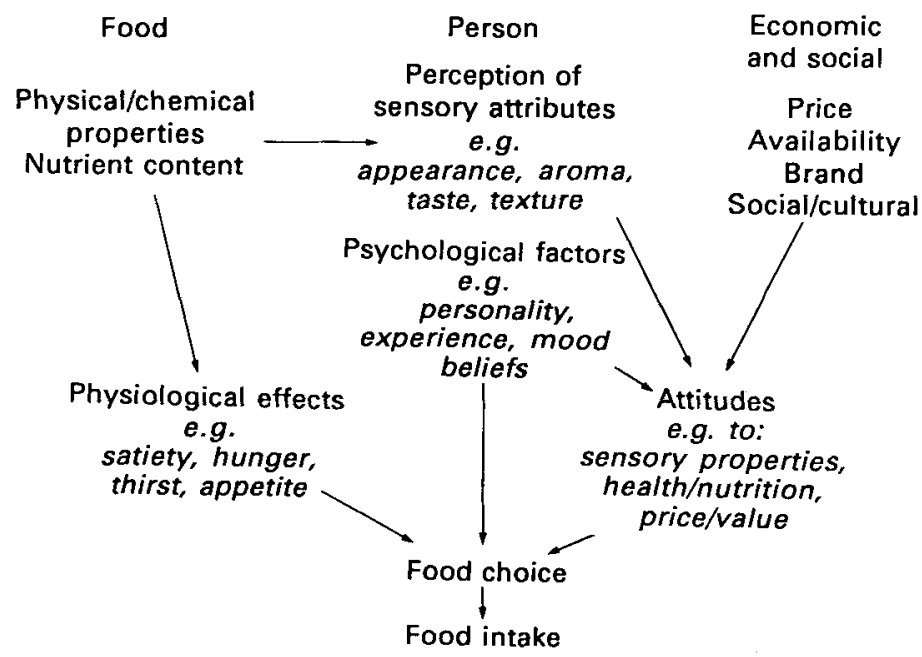

Fig. 1. Some factors affecting food choice and intake

several attempts to produce an overview of the type of potential influences (Pilgrim, 1957; Solms \& Hall, 1981; Shepherd, 1985; Booth \& Shepherd, 1988).

The scheme shown in Fig. 1 attempts to summarize some of the potential influences. The factors are split into those related to the food, to the person making the choice and to the environment external to both the food and the person. The food has certain properties related to its chemical and physical composition. These give rise to properties of the food which are perceived by the individual as sensory characteristics, such as appearance, taste, odour and texture. Taste is the perception of a chemical solution in contact with taste buds on the tongue. The common use of the term taste also incorporates perception of odours as gaseous chemicals at the back of the nose. When consuming foods both types of stimuli are perceived together and the impression is of one overall flavour rather than two distinct sensory inputs. It is of course common to smell odours through the nose without any accompanying taste stimulus, but the reverse is not true in ordinary circumstances. There are four basic tastes of salty (e.g. sodium chloride), sweet (e.g. sucrose), sour (e.g. citric acid) and bitter (e.g. quinine). Variations in flavour are much more varied than this would imply because of the combinations of taste with the perception of a large variety of odours. In addition to the basic tastes and the olfactory stimulation produced by foods a number of foods produce an irritant effect by trigeminal stimulation. This is most commonly true for spices, such as chilli, and even in cultures where such foods are commonly used children do not generally like them. However, they come to like these foods through gradual exposure in an appropriate context, and in some cultures they form a major part of the cuisine (Rozin \& Schiller, 1980; Rozin, 1982).

Sensory characteristics of themselves do not lead to food acceptance or rejection. There are large differences between individuals in their liking or preference for particular foods, or for the level of a sensory attribute in a food. Thus, it is neither the physical-chemical properties of the food nor the perception of these which determine liking, but preferences by the individual for certain types of attributes in a type of food.

The chemical components of a food may also be thought of in terms of nutrients, such as protein, fat, carbohydrate, or minerals. Physiological effects following ingestion of foods may influence subsequent choice (Booth et al. 1982; Blundell et al. 1987). These effects are likely to operate through the association between the physiological consequences of 
ingesting the foods and the sensory attributes of those foods (Booth et al. 1982), making liking for the foods higher on subsequent occasions. There is evidence that this type of mechanism operates for specific nutrients as well as energy (Blundell et al. 1987).

There will also be psychological factors which may influence food choice, e.g., personality (Shepherd \& Farleigh, $1986 a, b$ ). Part of this effect might be through differences in the lifestyle of individuals with different personality types. Differences between individuals in previous experience and learning associated with foods will lead to differences in beliefs, values and habits concerning particular foods. Likewise, for particular occasions there will be foods which are seen as more or less appropriate (Schutz et al. 1975). Differences in age, social class, education, region of residence, degree of urbanization will all lead to differences in food consumption. These may operate through some of the other variables described previously.

External to both the individual and the food are the general social and cultural environment. Food choice varies between cultures (e.g. Simoons, 1982) and the social milieu surrounding the individual will have an impact on food choice. The availability, including the convenience of purchase, of the food, its price and aspects such as packaging, advertising and marketing will all have an influence.

The previous discussion should not be taken as indicating a stationary position for these influences, but rather that there will be both short-term changes, brought about by ingestion of specific foods, and long-term changes brought about by experience and learning (Rozin, 1982). One short-term effect is the role of variety in eating. It is a wellestablished phenomenon that consuming particular foods will lead to a reduction of liking for that food in the short term and a reduction of the intake of that food. This has a biological utility for omnivores in that short-term changes in preferences will lead the animal to consume a variety of foods, and this will be much more likely to provide a balance of nutrients than if the animal consumes only its favourite food. The action of variety appears to take place through what has been termed sensory-specific satiety (Rolls et al. 1982). It is the sensory aspects of the foods which lead it to be liked less and hence this will generalise to other foods with similar sensory attributes. For naturally occurring foods this will often mean foods with similar nutrient composition.

\section{RELATIVE IMPORTANCE OF SENSORY ATTRIBUTES IN DETERMINING FOOD CHOICE}

Liking for foods is widely regarded as a very important determinant of food choice and for this reason there has been a great deal of work investigating liking or preferences for types of foods, in particular by the U.S. Army (e.g. Peryam et al. 1960). It is often assumed that preferences will relate to consumption, and hence preferences are often assessed on the assumption that they will predict consumption. There have been a number of studies testing this relationship, and in general those subjects rating a food as highly liked are more likely to consume that food than are subjects rating it lower in liking, although the relationship is not perfect (Peryam et al. 1960; Randall \& Sanjur, 1981). It is not clear how much such preferences for foods are the result of preferences for sensory attributes or complex preferences influer,ced by many of the other factors described previously (Randall \& Sanjur, 1981).

One method for trying to determine the relative importance of different types of influence is to ask people for ratings of importance. Schafer (1978) found husbands rated flavour as the most important determinant of food choice, whilst wives rated nutrition as most important with flavour second. McNutt et al. (1986) found safety was rated highest 
followed by flavour. One problem with this type of approach is that people might not be aware of what is influencing their choices.

An alternative procedure is to obtain responses from subjects in relation to foods and then to see how closely these relate to actual or reported consumption of foods. In a series of studies, Krondl \& Lau (1982) have looked at the perception by individuals of the price, convenience, prestige, health beliefs and flavour of foods, and how these relate to consumption. It is important to note that factors such as price are not actual price in this context but are the ratings given by subjects on a scale of 'very cheap' to 'very expensive'. Use is then made of the individual differences in perception of factors, such as price or flavour, for a particular food and a correlation is calculated for each food; the expectation is that those subjects saying that the flavour of a particular food is good will be more likely to buy or eat that food. Krondl \& Lau (1982) have found that, for the vast majority of foods included in their studies, the major determinant of consumption is the flavour (or taste) of the food, health beliefs tended to have the second highest number of significant correlations. Price and convenience were found to be unimportant, whilst the importance of prestige varied among subject groups.

Other studies have used models of attitudes and beliefs derived from social psychology, such as the one proposed by Fishbein \& Ajzen (1975), to try to determine the relative importance of different types of factors in relation to buying or eating particular types of foods. Shepherd \& Farleigh $(1986 a, b)$ found taste to be more important in determining table salt consumption, than beliefs about health consequences; the same was found to be true for consumption of snack foods (Shepherd, 1987). In a study in Finland, Tuorila (1987) found beliefs related to sensory aspects of milks varying in fat content to be slightly more important than health beliefs, although this was not found by Shepherd (1988) for low-fat milks in the UK.

Measures such as these are derived from rating the names of foods on general characteristics, such as how pleasant are the sensory attributes, or how 'healthy' the food is seen as being. If sensory characteristics do indeed relate closely to the choice of foods, then it should be possible to vary the sensory attributes and determine how much more or less the food will be consumed. In many cases this will have no nutritional impact since choosing one brand of a particular food over another brand will not generally lead to variation in nutrient intake. Nutrient intake will be influenced most by selection of different types of foods which will vary in many ways, and in these cases the specific role played by sensory factors will not be clear. There are, however, some specific components of foods which will have an effect both on the sensory attributes of the food and on the nutrients derived from consuming the food. Examples of these are salt, sugar and fat.

Before discussing attempts to relate intake of salt, sugar and fat to perceived sensory attributes, the types of sensory measures used will be briefly described.

\section{TYPES OF SENSORY MEASURES}

There are three main types of sensory measure used in studies of this type. These are threshold sensitivity, suprathreshold sensitivity and preference. The threshold is the concentration of a chemical which can just be perceived. Two types can be distinguished, a detection threshold where the subject is able to say that the sample differs from plain water, and a recognition threshold when the subject can identify what attribute is present, e.g. salty, sweet. The recognition threshold will be higher than the detection threshold.

Above absolute threshold there will be differential thresholds where the detection is between a lower and higher concentration of the same chemical. It is possible to develop a scale for assessing these above threshold levels from the 'just noticeable differences' at a 
succession of concentrations, but such a scale is easier to assess by asking subjects to rate stimuli on a scale of the intensity of the taste or smell (McBride, 1983). The most-common procedure is to ask subjects to rate the intensity of a stimulus, and these intensity ratings are plotted against the logarithm of the concentration of the constituent (e.g. sucrose). This is known as the psychophysical function and the slope of this function is taken as a measure of the subject's suprathreshold sensitivity. Suprathreshold intensity might be considered to be a more appropriate measure for relating to intake, since it is rare that a constituent is added until it is just detectable. This might be true in some cases, such as taints in food, where detectable levels will lead to rejection. With, for example, salt or sugar in a food the desired taste will often be well above threshold.

Measures of liking or preference would be expected to be even-more-closely related to intake than those of either threshold or suprathreshold sensitivity. This can be assessed in a number of ways, but the most common is some variation of the hedonic scale developed by Peryam \& Pilgrim (1957), which is a nine-category rating scale from 'Dislike extremely' through a neutral centre point of 'Neither like nor dislike' to 'Like extremely'. If ratings of this type are plotted against the logarithm of the concentration of a constituent they generally give a function which increases up to a maximum and then decreases as the concentration is increased further. The concentration with the maximum rating (sometimes referred to as the break point) is used as an indication of the preference for that constituent in the food. An alternative procedure giving similar results is to have subjects rate the pleasantness of samples. Other measures include presenting stimuli in pairs and asking subjects to indicate the one which is preferred, or providing samples with high and low concentrations of the constituent and asking the subject to mix them to his or her most preferred concentration. All these measures provide similar (although not always identical) information.

\section{RELATING SENSORY MEASURES TO INTAKE}

Before discussing the studies which have sought to relate sensory measures to intake some general points will be made. The first is that the evidence for a clear link is relatively weak. There is better evidence for preference being related to intake than for taste sensitivity relating to intake. This might in part be due to using inappropriate sensory measures, such as threshold, or to poor methodology for assessing either the sensory measures or intake. Alternatively the other factors discussed previously, which influence intake, might be more important. However, the possibility remains that the sensory measures, including preference are not major determinants of intake.

\section{SALT}

The hypotheses concerning sodium intake and taste have often been interrelated with the question of whether $\mathrm{Na}$ intake is related to hypertension, and some of the work has assumed this as a starting point. The assumption is that if high $\mathrm{Na}$ intake is related to high blood pressure, and various aspects of taste for salt (either in foods or solutions) are related to salt intake, then there should be differences between hypertensives and normals in their taste for salt. There are a number of steps in this hypothesis. The link between salt intake and hypertension is at best controversial (Simpson, 1979; Tobian, 1979; Brown et al. 1984), thus reducing the likelihood of finding relationships between taste and hypertension. However, much of the early work in this area started from this assumption and this will be reviewed first.

Mattes (1984) has reviewed the work on salt taste and hypertension, and in particular has drawn attention to a number of the methodological difficulties in this area. Richter (1936, 
1939) first suggested a link between taste sensitivity and salt intake, although he suggested that higher intake might be related to greater taste sensitivity. There is no evidence for this effect in humans. This hypothesis was reversed by Contreras (1978) to the hypothesis that higher salt intake would be related to lower sensitivity, i.e. those subjects who can taste the salt less will consume more in order to achieve a given taste level.

Evidence for differences in taste between hypertensives and normotensives will first be considered in terms of sensitivity at threshold. Fallis et al. (1962), Wotman et al. (1967), Bisht et al. (1971) and Merzon et al. (1981) found elevated thresholds in hypertensive patients compared with controls (i.e. they were less sensitive). Other studies have, however, failed to show such differences (Schechter et al. 1973; Henkin, 1974, 1980; Lauer et al. 1976). Threshold determination is time consuming and requires a large number of trials in order to get an accurate measure. Neither the positive nor negative studies in this area included sufficient trials for confidence in the conclusions drawn. Most of the studies involved stimulation of the whole mouth by the solution tasted, whereas other studies (e.g. Schechter et al. 1973; Henkin, 1974, 1980) involved placing drops of solution on the tongue; the former procedure might be more sensitive in detecting differences between the groups. Finally the adequacy of matching of controls to hypertensives is poor.

There have been few studies investigating suprathreshold sensitivity. Contreras (1978) cited a study by Moskowitz and Abramson on taste preference in obese and renal patients in which hypertensive patients had a lower suprathreshold sensitivity than normotensives. However, Bernard et al. (1980) and Mattes et al. (1983) both failed to find such differences between hypertensives and normals.

Preferences for salt would be expected to be much-more-closely related to intake and hence to hypertension, but the results are not clear. Bernard et al. (1980) found low-renin hypertensives to rate salt solutions more pleasant than controls, although this was a verysmall group of subjects and the justification for splitting the hypertensives into low- and high-renin groups is not compelling. Moskowitz and Abramson (cited by Contreras (1978)) found that hypertensives preferred higher concentrations of salt in soup. Apte (1980) found higher preferences with higher diastolic blood pressure in just one of many groups studied, but the relationship was not linear and hence impossible to interpret. Schechter et al. (1973) (also reported by Henkin, 1980) found that hypertensives drank more salt solution than controls when both were on a low-salt diet, which might be interpreted as an increased preference. Desor et al. (1975) found higher preference for salt in black American children and linked this with a higher incidence of hypertension in black American adults. Other studies have failed to find differences between hypertensives and normals in preferences for salt (Lauer et al. 1976; Mattes et al. 1983).

Thus studies with hypertensives offer some evidence for lower threshold sensitivity and higher preferences for salt in hypertensives. The few studies with suprathreshold sensitivity do not offer good evidence for any differences. In terms of the hypothesis that sensory measures are related to intake these studies are difficult to interpret since most have not included any measure of intake, even though this would be expected to mediate any effect on hypertension. In order to address this relationship directly we need to look at those studies which included some measure of intake.

The findings from studies including measures of intake are summarized in Table 1. The summary tables indicate those studies where any analysis has shown a significant effect. A ' 0 ' indicates that no significant effects were found, and blanks indicate that the relationship was not examined. It needs to be borne in mind that in many of the studies one significant effect may have occurred along with a large number of non-significant analyses.

Examining threshold sensitivity first, there is some evidence for lower sensitivity being related to higher intake. Chauncey et al. (1980) used a short questionnaire on salt intake 
Table 1. Studies examining the relationship between sensory measures and total salt intake

\begin{tabular}{|c|c|c|c|c|}
\hline Source & $\begin{array}{l}\text { Threshold } \\
\text { sensitivity }\end{array}$ & $\begin{array}{l}\text { Supra- } \\
\text { threshold } \\
\text { sensitivity }\end{array}$ & Preference & Comments \\
\hline Chauncey et al. (1980) & + & - & - & UV \\
\hline Pangborn \& Pecore (1982) & \pm & 0 & 0 & UV \\
\hline Mattes et al. (1983) & 二 & 0 & 0 & UV \\
\hline Shepherd et ai. $(1984 a)$ & - & 0 & 0 & - \\
\hline Shepherd et al. $(1984 b)$ & - & 0 & + & -- \\
\hline Chan et al. (1985) & - & $?$ & 0 & Unclear \\
\hline Elmer et al. (1985) & - & 0 & + & - \\
\hline Ishida et at. (1985) & 0 & + & - & - \\
\hline Bertino \& Chan (1986) & - & 0 & + & - \\
\hline Odeigah \& Obieze (1986) & + & $\ldots$ & - & UV \\
\hline Shepherd \& Farleigh $(1986 b)$ & - & - & + & - \\
\hline Mattes (1987) & - & 0 & 0 & Combination \\
\hline
\end{tabular}

,+ Results in predicted direction; 0 , no significant effect; -, results opposite to prediction; UV, unvalidated questionnaire used to assess intake; Combination, a combination of the variables was significantly related to intake.

and showed higher intake to be related to a higher threshold for salt in solution (i.e. lower sensitivity), although this was a weak effect shown only in one method of data analysis. Odeigah \& Obieze (1986) found a similar relationship in an African population. Pangborn \& Pecore (1982) assessed thresholds for salt in foods and solutions with normotensive subjects divided into low and high salt intake on the basis of a short questionnaire. They found thresholds for salt in solution were higher for the high-intake group, but the reverse was true for salt in tomato juice. These studies have all used unvalidated questionnaires as measures of intake, which might have reduced the chances of finding associations between sensory measures and intake. However, Ishida et al. (1985) used urinary excretion of $\mathrm{Na}$ as a measure of intake and failed to find any evidence for a relationship between threshold sensitivity and intake.

Suprathreshold sensitivity shows even less association with intake. Pangborn \& Pecore (1982) and Mattes et al. (1983), assessing intake by questionnaire, found no relationship between intake and suprathreshold sensitivity. This finding is common to studies using other measures of intake (Shepherd et al. $1984 a, b$; Elmer et al. 1985; Bertino \& Chan, 1986; Mattes, 1987). Chan et al. (1985) found one significant correlation between intake and the intercept of the intensity ratings of salt in rice, but this is not interpretable in terms of taste sensitivity. The one study to find a clear relationship was that of Ishida et al. (1985), who found a small but statistically significant relationship between urinary $\mathrm{Na}$ (from a single collection expressed relative to creatinine) and suprathreshold discrimination of salt in water and foods.

Preference shows more relationship with intake, although again the findings are far from clear. Pangborn \& Pecore (1982) and Mattes et al. (1983) failed to find any effects with intake assessed by unvalidated questionnaire, but even with other measures of intake there have been negative findings (Shepherd et al. 1984a; Chan et al. 1985; Mattes, 1987). There have, however, also been positive findings. Shepherd et al. $(1984 b)$ used a validated questionnaire to assess intake and found a relationship between preference measures and total salt intake. This was true only in some of the methodological variations included in the study. Shepherd \& Farleigh $(1986 b)$ found subjects with a low salt intake had a lower preference for salt in soup than those with a high intake; salt intake was assessed by $7 \mathrm{~d}$ 
complete urine collections. Elmer et al. (1985) also reported a positive relationship between $24 \mathrm{~h}$ urinary excretion of $\mathrm{Na}$ and preference for salt. Bertino \& Chan (1986) found $\mathrm{Na}$ intake from weighed food records to relate to preferences for salt in foods.

Mattes (1987) reported a study including intensity ratings of foods, along with adjusting food samples to the level of saltiness most preferred, questionnaires on frequency of consumption of salty foods and liking for salty foods. None of the measures related directly to intake assessed by $7 \mathrm{~d}$ weighed intake, two $24 \mathrm{~h}$ urine collections and discretionary salt by weighed salt pot. However, a discriminant analysis gave a function which related to total intake, which included intensity ratings for tomato juice, general preference for salty foods, and adjusting potato and water to the most-preferred concentration. These do not clearly relate to each other in any pattern, and it would be necessary to repeat the study with a second group of subjects in order to determine whether this combination of variables really does discriminate high from low intake subjects or whether it was simply a chance combination. However, this type of approach might prove useful in the future in combining sensory measures which assess different aspects of taste, and together might be more closely related to intake than any single sensory measure.

The evidence for total salt intake being closely related to sensory measures determined in the laboratory is not clear. There is some evidence for higher preferences being related to higher salt intake, and possibly for lower threshold sensitivity (but not suprathreshold sensitivity) relating to high salt intake. It should be noted that with one exception all of the significant results are in the predicted direction. Thus, even though a number of studies have failed to show any effects, where effects occur they do support the hypotheses of lower sensitivity and higher preferences leading to higher intake. This effect, however, appears not to be strong.

An alternative procedure, adopted in a number of studies, has been to investigate the relationship between taste and either table salt use or some measure of discretionary salt use. Depending on the definition of discretionary use, this might also include salt used in cooking. It might be expected that table-salt use would more closely relate to sensory measures, since it is more under the direct control of the individual than is total salt intake (Shepherd \& Farleigh, 1986b).

The results from studies investigating the relationship between sensory measures and table-salt use are summarized in Table 2. Maller et al. (1982) measured table-salt use in a controlled laboratory setting and had subjects rate intensity and pleasantness of salt in solution and in tomato juice. Although there was not a significant correlation between salt use and either the suprathreshold sensitivity or preference measures, the number of subjects included was very low. Shepherd et al. (1984a) measured table-salt use over a period of $7 \mathrm{~d}$ using weighed salt pots and obtained hedonic ratings for salt in foods and intensity for both foods and solutions. Subjects with high table-salt use were found to have lower suprathreshold sensitivity and higher preference than subjects with low table-salt use. Even in this case, only a few of the comparisons showed these differences. In a further study, Shepherd et al. (1984b) used a validated questionnaire to assess intake and found relationships between table-salt use and preference measures, but not suprathreshold sensitivity. Shepherd \& Farleigh (1986 b) again found higher preferences for salt in soup for high-table-salt users compared with low users; table-salt use was assessed using preweighed salt pots over $7 \mathrm{~d}$. Mattes (1987) found one correlation from a large number of correlations with a measure of discretionary salt use, but this was not an interpretable relationship. Whereas Mattes (1987) reported finding a combination of variables from a discriminant analysis which predicted total salt intake, no such combination could be found for discretionary use.

The results for table-salt use are similar to those for total intake, with some evidence for 
Table 2. Studies examining the relationship between sensory measures and table-salt use or discretionary salt use

\begin{tabular}{lccc}
\hline \hline \multicolumn{1}{c}{ Source } & $\begin{array}{c}\text { Supra- } \\
\text { threshold } \\
\text { sensitivity }\end{array}$ & Preference & Comments \\
\hline Maller et al. $(1982)$ & 0 & 0 & Few subjects \\
Shepherd et al. $(1984 a)$ & + & + & - \\
Shepherd et al. $(1984 b)$ & 0 & + & - \\
Shepherd \& Farleigh $(1986 b)$ & 0 & + & Unclear, \\
Mattes (1987) & & & discretionary \\
\hline
\end{tabular}

+ , Results in predicted direction; 0 , no significant effect.

higher preferences being related to higher intake, but little evidence for lower sensitivity playing a role. As with total salt intake, where significant results occur they are in the predicted direction, thus giving some support to there being a real effect, if not a strong one.

Overall, the relationship between intake and salt taste is far from clear. There are several potential reasons for this. The first is the measurement of total salt intake. It is difficult to determine $\mathrm{Na}$ intake from weighed-food records because it is added both in cooking and at the table. It can be argued that the best indicator of total intake will be urinary excretion of $\mathrm{Na}$, but this is very variable and in order to get a reasonable estimate of intake it will be necessary to have several complete urine collections (Farleigh et al. 1985). Many of the studies have used only a single $24 \mathrm{~h}$ collection or have used unvalidated questionnaires. If questionnaires are to be used in this type of study they need to be carefully validated to show that they give a reasonable estimate of salt intake (Shepherd et al. 1985; Shepherd \& Farleigh, 1987). Assessment of discretionary use can be achieved by using weighed salt pots or validated questionnaire. It might be useful to differentiate table use from cooking use, since the former is more under the control of the individual (Shepherd \& Farleigh, $1986 b)$.

The second problem relates to the appropriate taste measures to assess. It is most likely that intake will relate to preference, and if it is related to sensitivity then this would be likely to operate through differences in preferences. Therefore, preference should be the primary taste measure investigated and sensitivity should be looked at as an addition to this. Suprathreshold sensitivity using ratings of intensity is more closely related to normal eating and hence preferable to threshold determinations in this context. Whilst it might be appealing to use salt solutions for assessment, these lack ecological validity for preference assessment, since people do not normally consume salted water; hence it is preferable to assess the taste for salt in real foods. This leads to a problem of the types of food to assess. Even confining the choice to those foods normally salted there will still be a large number of possibilities. If more than one food is included and the results are inconsistent, this might mean that people do not have a consistent liking for high or low salt levels across foods which might normally be salted. Shepherd et al. (1987), however, found that when careful assessment is made of a subject's most preferred concentration of salt in several very different foods, there is very good agreement between the preferences for salt levels in the foods, i.e. those subjects with a high preference in one food will have high preferences in other foods. More likely the discrepancy between the findings for different foods is that the information obtained at the level of individual subjects is not sufficiently accurate to serve 
as a measure in this type of study. Since it is required to relate the sensory and intake measures at the individual level it is necessary to obtain enough information under sufficiently controlled conditions to be able to differentiate between individual subjects. It is not possible to have, for example, just one assessment from each subject and then average over subjects (as might be the case in sensory evaluation of foods), since it is the differences between individuals which are important. Including measures with high variability will obscure any real relationships between variables and will lead to an attenuation of any correlations (see Guilford, 1954; Shepherd et al. 1985). An alternative procedure is to take more than one type of measure and to combine them as did Mattes (1987). It is necessary in this case to obtain a discriminant function from one set of data and then to test this with an independent set of data, otherwise spurious combinations of variables may be found for each independent data set.

Even with accurate measures of both intake and sensory variables there are still only weak relationships between taste and intake. In the case of total intake this might not be too surprising since the majority of $\mathrm{Na}$ in the diet is derived from foods rather than added by the individual; recent studies have put the amounts derived from food at about $85 \%$ of total intake (Sanchez-Castillo et al. 1984; Shepherd \& Farleigh, 1986b; Williams \& Bingham, 1986). Some of the most-important sources of $\mathrm{Na}$ in the diet are not considered salty, e.g., bread, breakfast cereals, milk, and in general there are not low-salt equivalents. Thus differences between individuals in the amounts of $\mathrm{Na}$ derived from these foods would be because the individual consumes more or less of the food rather than chooses a lowersalt example of the same type of food. It would be unlikely if consumption of these foods were very highly influenced by liking for the salty taste, rather consumption of foods such as bread will be determined by a large number of other factors and the $\mathrm{Na}$ intake will in part be incidental. It would therefore be expected that the relationship between even preference and total salt intake would be only relatively low. Even though the sensory attributes of saltiness might be less important in determining selection of these foods, that is not to say that preferences for other sensory attributes of the foods are not important.

An alternative view is to look at table salt use. Here intake is under voluntary control and hence it would be expected that there would be a much clearer relationship with taste preference. Although the relationship might be stronger than with total intake (Shepherd et al. 1984a, $b$; Shepherd \& Farleigh, 1986b) it is still relatively weak. Some intriguing work on this question by Greenfield et al. (1983) involved manipulating the size of the hole in table-salt pots and hence the rate of delivery. This suggested that people added salt through habit rather than to individual taste, although the subjects only had one experience of the salt pots and hence could not learn to adjust their use to take account of the different hole sizes. We have recently replicated this finding with about 2500 subjects using a canteen over a period of time. In this case, experience with the different salt pots showed no learning over $10 \mathrm{~d}$ and there were large effects of habit rather than salting the food to taste. Thus even in this case other factors are important in addition to purely sensory ones.

\section{SUGAR AND FAT}

Many of the problems discussed previously also apply in the case of investigating the relationships between intake and sensory responses to sugar and fat in foods.

With both sugar and fat in foods the interest has generally been in body-weight. In both cases the expectation is that differences between individuals in perception or liking of sweetness or creaminess in foods will lead to greater ingestion of these nutrients, and that greater ingestion of these will lead to higher body-weights and possibly obesity. As in the example of salt and hypertension, there are a number of links in this chain and the simplest 
is that the sensory effects will be related to intake. Most of the work, however, has started from the point of assessing perception of food samples in groups of subjects with different body-weights.

Grinker et al. (1972) found no differences between obese and normal weight subjects in perceived sweetness intensity of sucrose solutions. There have since been a number of studies investigating threshold or suprathreshold sensitivity to sugars either in solution or in foods, which have failed to show differences between overweight and normal subjects (Rodin, 1975; Grinker et al. 1976; Malcolm et al. 1980; Witherly et al. 1980; Frijters \& Rasmussen-Conrad, 1982). Likewise suprathreshold sensitivity is not affected by shortterm restriction of energy intake (Drewnowski \& Greenwood, 1983) nor following weight loss (Grinker et al. 1976).

There is thus no evidence for taste sensitivity, either at threshold or above, being related to body-weight.

As with salt taste and hypertension, it might be expected that preferences would be more closely related to body-weight. Pangborn \& Simone (1958) found that overweight individuals gave higher hedonic ratings to all concentrations of sugar in canned fruits and ice cream than normal-weight individuals. This might imply that they like the foods more but not that they like them sweeter. Cabanac \& Duclaux (1970) found obese subjects had a higher preference for sucrose in solution than did normals. Rodin et al. (1976) also found a correlation between sweetness preferences and body-weight, but several studies have failed to find any relationship (Rodin, 1975; Thompson et al. 1976). Still further studies have found results opposite to the predicted direction. Grinker $(1975,1977)$ and Grinker et al. (1976) found obese children and adults preferred lower sweetness in solutions and a flavoured drink; a finding confirmed in other studies (Enns et al. 1979; Johnson et al. 1979).

Some of the discrepancies in these findings might be due to differences in the types of subjects studied or to procedural variations. However, they do not offer firm support for the hypothesis of heavier subjects having higher preferences for sweetness or lower sensitivity to sweetness.

The relation between body-weight and sensory measures is based on the premise that preferences for higher concentrations of sugar assessed in the laboratory will relate to intake of sugar or sweet foods. Studies including such assessments are shown in Table 3. Pangborn \& Giovanni (1984) found neither suprathreshold sensitivity nor preferences for sucrose in lemonade related to intake of sweet foods estimated from an unvalidated questionnaire. Bertino \& Chan (1986) used a $3 \mathrm{~d}$ dietary record and likewise found no relationship between intake of sweet foods and suprathreshold sensitivity or preference. Mattes (1985) used $7 \mathrm{~d}$ dietary records and failed to find any relationships between intake and single taste measures of threshold or suprathreshold sensitivity, or preference for sweetness and bitterness in solutions or foods. They did, however, find the percentage of energy derived from sweet foods to be related to a combination of the sweet-taste measures, and percentage of energy from bitter foods to be related to a combination of the bitter-taste variables. There was not a consistent pattern in these combinations which were derived from discriminant analyses (see previous discussion relating to Mattes, 1987). Mattes \& Mela (1986) did find significant relationships between eating sweet foods and preferences for sweetness in test foods. They repeated the type of data analysis used by Mattes (1985) and again found the percentage of energy derived from sweet foods related to a combination of sweet-taste measures, and that the proportion of energy derived from carbohydrate was also related to a combination of taste measures. The discriminant function developed by Mattes \& Mela (1986) was different from that found by Mattes (1985) since the variables included in the earlier study were not exactly the same. Thus, this 
Table 3. Studies examining the relationship between sensory measures and sugar and fat intake

\begin{tabular}{|c|c|c|c|c|}
\hline Source & $\begin{array}{l}\text { Threshold } \\
\text { sensitivity }\end{array}$ & $\begin{array}{l}\text { Supra- } \\
\text { threshold } \\
\text { sensitivity }\end{array}$ & Preference & Comments \\
\hline \multicolumn{5}{|l|}{ Sugar } \\
\hline Pangborn \& Giovanni (1984) & - & 0 & 0 & UV \\
\hline Mattes (1985) & 0 & 0 & 0 & Combination \\
\hline Mattes \& Mela (1986) & - & -- & + & Combination \\
\hline Bertino \& Chan (1986) & - & 0 & 0 & - \\
\hline \multicolumn{5}{|l|}{ Fat $:$} \\
\hline Pangborn \& Giovanni (1984) & _- & 0 & 0 & UV \\
\hline Pangborn et al. (1985) & 0 & 0 & + & UV \\
\hline
\end{tabular}

,+ Results in predicted direction; 0 , no significant effect; UV, unvalidated questionnaire used to assess intake; Combination, a combination of the variables was significantly related to intake.

cannot be taken as an adequate test of the discriminant function generated by Mattes (1985) but rather represents a separate set of variables being combined in a different way to predict aspects of intake.

Although the sweetness of sugar has been investigated most in relation to overweight, it is more likely that a high fat intake will lead to excessive energy intake because of its high energy density. The sensory aspects of fat are not as easily investigated as those of sugars, but differences in fat content do impart different sensory characteristics to a food, mainly in terms of texture and mouthfeel.

Studies involving fat are again shown in Table 3. Pangborn \& Giovanni (1984) failed to find any relationship between either suprathreshold sensitivity or preference for fat levels in milk and fat intake assessed by unvalidated questionnaire. Pangborn et al. (1985) did find that preference for fat levels in milk was related to questionnaire-assessed fat intake but not to body-weight. In the same study, threshold and suprathreshold sensitivity were neither related to fat intake nor to body-weight.

Thus, as with sugar and sweet foods, the evidence for taste responses to fat being closely related to fat intake is very poor, although there is some evidence that preference may relate to fat intake.

Drewnowski et al. (1985) have proposed that foods which are high in energy are often high in both sugar and fat, and that considering either alone will be unlikely to show meaningful relationships with body-weight. Obese subjects were found to prefer milk containing more fat but less sugar than normal subjects, but reduced obese subjects preferred a mixture higher in both fat and sugar. Measuring the liking for sugar at single levels of fat would have led to different relationships between body-weight and preference, and may account for some of the discrepancies in the literature. The subject groups did not differ in suprathreshold sensitivity.

Thus, as for salt, the evidence for a relationship between preference and intake is stronger than between sensitivity and intake, but there are a number of methodological problems with many of the studies. The relationship between taste and body-weight is less clear.

\section{DIETARY MANIPULATIONS}

The previous discussions of the relationships between sensory responses and intake have all been correlational in the sense of looking for an existing relationship within a population. 
Table 4. Studies examining the effects on sensory measures of a low-or high-salt diet

\begin{tabular}{|c|c|c|c|c|}
\hline Source & $\begin{array}{l}\text { Threshold } \\
\text { sensitivity }\end{array}$ & $\begin{array}{l}\text { Supra- } \\
\text { threshold } \\
\text { sensitivity }\end{array}$ & Preference & Comments \\
\hline \\
\hline Henkin et al. (1963) & 0 & - & - & - \\
\hline Stinebaugh et al. (1975) & 0 & - & - & - \\
\hline Gillum et al. (1981) & 0 & - & Decrease & Nearly significant \\
\hline Bertino et al. (1981) & - & Decrease & Increase & Few subjects \\
\hline Bertino et al. (1982) & - & Increase & Decrease & - \\
\hline Chan et al. (1985) & - & 0 & 0 & - \\
\hline Elmer et al. (1985) & - & ? & Decrease & Unclear \\
\hline Marya et al. (1985) & Decrease & - & - & - \\
\hline Blais et al. (1986) & - & $\mathbf{0}$ & Decrease & - \\
\hline \multicolumn{5}{|l|}{ High-salt diet: } \\
\hline Bertino et al. (1986) & - & 0 & Increase & - \\
\hline
\end{tabular}

0 , No significant effect.

Although it might be supposed that the differences in sensory variables will lead to the differences in intake (or in hypertension or body-weight) this is not the only possible interpretation of such a relationship. It is also possible that people have different intakes of salt, sugar or fat for reasons other than the sensory factors and that this diet leads them to have particular preferences (or indeed sensitivity) for the sensory attributes. It is not possible to be entirely clear about the direction of causality. Except in diseases, it is not generally easy to alter taste perception or preferences, but it is relatively easy to manipulate the diets of individuals and to determine whether this affects their sensory responses. As previously the examples of saltiness and sweetness will be considered.

The effect of salt in the diet on voluntary salt intake has been studied widely in animals and in particular in rats (e.g. Richter, 1956). In this literature the effect of $\mathrm{Na}$ deprivation tends to be increased preference for salt, which would return the rat to its normal $\mathrm{Na}$ balance.

Results from human studies are summarized in Table 4. Subjects placed on very-low-salt diets have been reported to have lowered thresholds (i.e. the subject is more sensitive to the taste of salt) (Yensen, 1959) but other studies have failed to find such an effect (Henkin et al. 1963; Stinebaugh et al. 1975; Gillum et al. 1981). Others have reported higher thresholds for patients on moderately-low-Na diets against those on normal diets (Marya et al. 1985). Bertino et al. (1981) found decreased suprathreshold sensitivity and increased preference in three subjects after $24 \mathrm{~d}$. Bertino et al. (1982) studied subjects on a low-Na diet for 5 months and found increases in the slope of the psychophysical function (i.e. increased suprathreshold sensitivity) for one of the foods tested, along with decreases in preferences for salt in foods but not solutions. Blais et al. (1986) replicated the finding for decreased preference over 1 year on a low-salt diet but failed to find differences in suprathreshold sensitivity. Gillum et al. (1981) found a decrease in preference, which approached statistical significance. Elmer et al. (1985) found evidence for a decreased preference but the effects for suprathreshold sensitivity were unclear. Chan et al. (1985) failed to find any effect of reducing $\mathrm{Na}$ in the diet on either suprathreshold sensitivity or preference measures. Bertino et al. (1986) investigated taste changes when subjects increased their salt intake over a 4-week period. They found increased preference for salt 
in those subjects who increased their salt intake by adding salt to their food. However, subjects who took salt in the form of salt tablets, thus getting the salt into their bodies but not experiencing any more salty tastes over the experimental period, showed no increase in preferences. Subjects taking placebo tablets likewise showed no changes. Bertino et al. (1986) found no effects of the diet on suprathreshold sensitivity.

Thus for sensitivity at and above threshold the evidence for any effect of the diet is equivocal. For preference there is reasonably good evidence that a reduction in salt in the diet leads to lower preferences for salt, and conversely an increase in salt in the diet leads to increased preferences.

Some of the differences between the results for sensitivity might be due to differences in the degree of restriction of the diet. In animal studies, the animals will generally be in a need state, whereas in most of the human studies the level of restriction is not sufficient to bring this about. It is, therefore, probably not wise to extrapolate from the animal literature to taste responses in humans. The preference effects found by Bertino et al. (1981) are contrary to other findings with humans. It is unlikely that this is because the time on the diet was shorter, since Blais et al. (1986) and Bertino et al. (1986) included measurements at short intervals. More likely it is due to the low number of subjects (three) included in the study.

Whereas experiences with tastes of foods will be complex in adults, infants will have relatively limited experience and hence it should be possible to investigate the effects of these early experiences on infant preferences. Harris \& Booth (1985) examined the relationship between experiences with salty foods and preferences for salt levels in a food in 6-month-old infants and found evidence for the experience leading to higher preferences. A similar finding was obtained for sweet taste by Beauchamp \& Moran (1982) with infants fed on sweetened water showing preferences for higher concentrations of sucrose.

The results are in agreement with most of the results shown in Table 4 for changes in preferences in adults when the diet is modified. However, in the case of adults the picture is likely to be more complicated. In the infant studies there is a clear effect of experience of particular tastes in the diet leading to preferences for those tastes in foods.

\section{EFFECTS OF DISEASES ON SENSORY RESPONSES}

Many diseases and medications have an effect on the perception of both taste and odour. Studies in this area have been reviewed by Galili (1982), and Schiffman (1983a,b) has listed studies reporting disorders of taste and smell in different diseases and with various drug treatments. Many of these reports are, however, not systematic studies of actual taste and olfactory function but often rely on patients' own anecdotal reports of changes in sensory function.

The effects are often in the form of generalized or more specific reductions in sensory sensitivity. These have been shown for a wide variety of patients including cancer patients receiving radiotherapy (Mossman \& Henkin, 1978), diabetics (Settle, 1986), hyperthyroid patients (Mattes et al. 1986), multiple sclerosis (Catalanotto et al. 1986) and head injury (Costanzo \& Becker, 1986). There have, however, been reports of increased taste sensitivity to bitter tastes in cancer patients (DeWys, 1977), which might then influence the dietary selection of patients. This effect has not been found in all studies of cancer patients (see Galili, 1982). Zinc deficiency has been shown to be associated with reduced taste sensitivity (e.g. Henkin, 1984; Ishida et al. 1985). Brown et al. (1986) failed to find differences in preferences for nutritional supplements between cancer patients and controls. Doty (1977) found patients with congenital anosmia (absence of ability to smell) and controls gave very similar preference ratings to food names, although there were some variations.

Although the interest in sensory responses in patients with different pathologies is often 
felt to lead to problems of nutritional intake, very few studies have systematically demonstrated the effects of abnormalities of taste or olfaction on intake. Mattes-Kulig \& Henkin (1985) found patients with taste abnormalities (resulting from a variety of causes) had lower energy intake than controls, resulting in reduced intake of various nutrients. Ferris et al. (1986) found lower scores for enjoyment of food in anosmics, but failed to find any substantial differences in measures of food consumption and nutritional status.

Even in cases where diseases or medication affect the diet and taste or olfaction changes, it is not generally possible to be sure that the dietary changes are due to sensory changes. In all disease states and with many forms of medication there will be unpleasant experiences for the patient, and if these were associated with particular foods, liking for those foods will be reduced through associative conditioning (Midkiff \& Bernstein, 1985; Mattes, 1986). Thus it is not possible to generalize from these clinical populations to the role of sensory perception in determining eating in normal subjects.

\section{CONCLUSIONS}

Sensory attributes of foods are one of many aspects which will influence people's choice of foods and hence their nutrient intake. In studies looking at the relative importance of different factors in influencing food choice sensory attributes are found to be very important. Likewise studies of preferences for particular foods show these to be closely related to consumption of the foods.

Whilst patients suffering from a variety of pathological conditions have been found to have abnormalities in sensory responses, the effects of these abnormalities on dietary intake are not so clear. Even in cases where there are differences in food intake this might be due to aversive conditioning of the flavours rather than to abnormalities in sensory response as such.

Although sensory attributes of the foods are found to be important in general studies of factors influencing food choice when specific sensory measures on foods in the laboratory are related to nutrient intake or food consumption, in the real world the picture is much less clear. The examples of intake of salt, sugar and fat have not given convincing evidence for the sensory attributes playing a major role in determining intake. Preferences are more clearly related to intake than are threshold or suprathreshold sensitivity, but even in the case of preferences the relationship is relatively weak. A number of methodological problems might account for some of the lack of results. Many studies have assessed intake inadequately, often using short unvalidated questionnaires or other measures of insufficient accuracy. Such poor estimates of intake would obscure any association between the sensory attributes and intake. Likewise many of the sensory measures have been inappropriate or not measured to a sufficient accuracy. The use of solutions rather than foods and of threshold determinations lacks ecological validity. The measures most likely to relate to intake are those most closely related to eating normal food, i.e. the tastants in foods at above threshold levels normally found in foods. Preferences would be more likely than sensitivity to relate to intake and hence should be investigated as the primary sensory measure, followed by suprathreshold sensitivity. As with the intake measures, it is necessary to be confident in the measures at the level of individual subjects, since variability in the measures will reduce any apparent relationships. In order to achieve this it is necessary to have repeated assessments by the same subjects under carefully controlled conditions. Since different types of measures may assess different sensory aspects, it might be useful to use a variety of different types of measures and to combine these in order to predict intake.

Few studies meet these criteria, but even those which do show the sensory attributes assessed to be only part of the picture. However, individual foods are chosen not because 
of a single sensory attribute, such as saltiness or sweetness, but for a number of sensory attributes, and when choice of the whole diet is examined there will be a complex array of sensory attributes influencing choice. Likewise the other factors discussed earlier such as availability, price, convenience, beliefs about nutritional benefits, along with advertising, brand image and cultural and social influences will all play a part, along with sensory determinants. Given this complex array of factors it is not surprising that single sensory attributes do not relate closely to intake of nutrients, but the sensory attributes need to be considered in the context of these wider factors.

\section{REFERENCES}

Apte, J. K. (1980) The relationship between blood pressure levels, diet, weight perception, salt preference and psycho-social stress. Ph.D. Thesis, University of North Carolina.

Beauchamp, G. K. \& Moran, M. (1982). Dietary experience and sweet taste preference in human infants. Appetite 3, $139-152$.

Bernard, R. A., Doty, R. L., Engelman, K. \& Weiss, R. A. (1980). Taste and salt intake in human hypertension. In Biological and Behavioral Aspects of Salt Intake, pp. 397-409 [M. R. Kare, M. J. Fregly and R. A. Bernard, editors]. New York: Academic Press.

Bertino, M., Beauchamp, G. K. \& Engelman, K. (1982). Long-term reduction in dietary sodium alters the taste of salt. American Journal of Clinical Nutrition 36, 1134-1144.

Bertino, M., Beauchamp, G. K. \& Engelman, K. (1986). Increasing dietary salt alters salt taste preference. Physiology and Behavior 38, 203--213.

Bertino, M., Beauchamp, G. K., Riskey, D. R. \& Engelman, K. (1981). Taste perception in three individuals on a low-sodium diet. Appetite 2, 67-73.

Bertino, M. \& Chan, M. M. (1986). Taste perception and diet in individuals with Chinese and European backgrounds. Chemical Senses 11, 229-241.

Bisht, D. B., Krishnamurthy, M. \& Rangaswamy, R. (1971). Studies on threshold of taste for salt with special reference to hypertension. Indian Heart Journal 23, 137-140.

Blais, C. A., Pangborn, R. M., Borhani, N. O., Ferrell, M. F., Prineas, R. J. \& Laing, B. (1986). Effect of dietary restriction on taste responses to sodium chloride: a longitudinal study. American Journal of Clinical Nutrition 44, 232-243.

Blundell, J. E., Rogers, P. J. \& Hill, A. J. (1987). Evaluating the satiating power of foods: implications for acceptance and consumption. In Food Acceptance and Nutrition, pp. 205-219. [J. Solms, D. A. Booth, R. M. Pangborn and O. Raunhardt, editors]. London: Academic Press.

Booth, D. A., Lee, M. \& McAleavey, C. (1976). Acquired sensory control of satiation in man. British Journal of Psychology 67, 137-147.

Booth, D. A., Mather, P. \& Fuller, J. (1982). Starch content of ordinary foods associatively conditions human appetite and satiation, indexed by intake and eating pleasantness of starch-paired flavours. Appetite 3, 163-84.

Booth, D. A. \& Shepherd, R. (1988). Sensory influences and food acceptance. BNF Nutrition Bulletin 13, 39. 54.

Brown, J. J., Lever, A. F., Robertson, J. I. S., Semple, P. F., Bing, R. F., Heagerty, A. M., Swales, J. D., Thurston, H., Ledingham, J. G. G., Laragh, J. H., Hansson, L., Nicholls, M. G. \& Espiner, A. E. (1984). Salt and hypertension (comments on NACNE). Lancet ii, 456.

Brown, R. O., Pharm, D., Schlegel, K., Hall, N. H., Bernard, S. \& Heizer, W. D. (1986). Taste preferences for nutritional supplements : comparison of cancer patients and healthy controls using a wine-tasting scale. Journal of Parenteral and Enteral Nutrition 10, 490-493.

Cabanac, M. (1979). Sensory pleasure. Quarterly Review of Biology 54, 1-29.

Cabanac, M. \& Duclaux, R. (1970). Obesity: absence of satiety aversion to sucrose. Science 168, $496-497$.

Catalanotto, F. A., Dore-Duffy, P. \& Donaldson, J. O. (1986). Taste and smell function in multiple sclerosis. In Clinical Measurement of Taste and Smell, pp. 519-528 [H. L. Meiselman and R. S. Rivlin, editors]. New York: Macmillan.

Chan, M. M., Garey, J. G., Levine, B., McRae, J. E. \& Terpenning, I. (1985). Moderate dietary reduction and salt taste perception of normotensive individuals with family history of hypertension. Nutrition Research $\mathbf{5}$, 1309-1319.

Chauncey, H. H., Wallace, S. \& Alman, J. E. (1980). Salivary chloride levels, taste thresholds for salt, and food ingestion. In Biological and Behavioral Aspects of Salt Intake, pp. 113-125 [M. R. Kare, M. J. Fregly and R. A. Bernard, editors]. New York: Academic Press.

Contreras, R. J. (1978). Salt taste and disease. American Journal of Clinical Nutrition 31, $1088-1097$.

Costanzo, R. M. \& Becker, D. P. (1986). Smell and taste disorders in head injury and neurosurgery patients. In 
Clinical Measurement of Taste and Smell, pp. 565-578 [H. L. Meiselman and R. S. Rivlin, editors]. New York: Macmillan.

Desor, J. A., Greene, L. S. \& Maller, O. (1975). Preferences for sweet and salty in 9- to 15-year-old and adult humans. Science 190, 686-687.

DeWys, W. D. (1977). Changes in taste sensation in cancer patients: correlation with caloric intake. In The Chemical Senses and Nutrition, pp. 381-391. [M. R. Kare and O. Maller, editors]. New York: Academic Press.

Doty, R. L. (1977). Food preference ratings of congenitally anosmic humans. In The Chemical Senses and Nutrition, pp. 315-325 [M. R. Kare and O. Maller, editors]. New York: Academic Press.

Drewnowski, A., Brunzell, J. D., Sande, K., Iverius, P. H. \& Greenwood, M. R. C. (1985). Sweet tooth reconsidered: taste responsiveness in human obesity. Physiology and Behavior 35, 617-622.

Drewnowski, A. \& Greenwood, M. R. C. (1983). Cream and sugar: human preferences for high-fat foods. Physiology and Behavior 30, 629-633.

Elmer, P. J., Grimm, R. H., Svendsen, K., Prineas, R. J. \& Clearman, D. (1985). Sodium taste preference changes in response to low-sodium diet in hypertensives. American Heart Association Monograph 72, Suppl. III, 186.

Enns, M. P., Van Itallie, T. B. \& Grinker, J. A. (1979). Contributions of age, sex, and degree of fatness on preferences and magnitude estimations for sucrose in humans. Physiology and Behavior 22, 999-1003.

Fallis, N., Lasagna, L. \& Tetreault, L. (1962). Gustatory thresholds in patients with hypertension. Nature 196, 74-75.

Fantino, M. (1984). Role of sensory input in the control of food intake. Journal of the Autonomic Nervous System 10, 347-358.

Farleigh, C. A., Shepherd, R. \& Land, D. G. (1985). Measurement of sodium intake and its relationship to blood pressure and salivary sodium concentration. Nutrition Research 5, 815-826.

Ferris, A. M., Schlitzer, J. L. \& Schierberl, M. J. (1986). Nutrition and taste and smell deficits : a risk factor or an adjustment? In Clinical Measurement of Taste and Smell, pp. 264-278 [H. L. Meiselman and R. S. Rivlin, editors]. New York: Macmillan.

Fishbein, M. \& Ajzen, I. (1975). Belief, Attitude, Intention and Behavior: An Introduction to Theory and Research. Reading, MA: Addison-Wesley.

Frijters, J. E. R. \& Rasmussen-Conrad, E. L. (1982). Sensory discrimination, intensity perception, and affective judgment of sucrose-sweetness in the overweight. Journal of General Psychology 107, 233-247.

Galili, D. (1982). Disordered taste sensation in systemic diseases in man : a review. In Determination of Behaviour by Chemical Stimuli, pp. 219-232 [J. E. Steiner and J. R. Ganchrow, editors]. London: IRL Press.

Gillum, R. F., Prineas, R. J., Anderson, P. \& Kebede, J. (1981). Lack of response of salt taste threshold and preference to dietary sodium restriction in mild hypertension. American Heart Journal 102, 138.

Greenfield, H., Maples, J. \& Wills, R. B. H. (1983). Salting of food - a function of hole size and location of shakers. Nature 301, 331-332.

Grinker, J. (1975). Obesity and taste: sensory and cognitive factors in food intake. In Obesity in Perspective, pp. 73-80 [G. Bray, editor]. Washington, DC: US Government Printing Office.

Grinker, J. (1977). Effects of metabolic state on taste parameters and intake: comparisons of human and animal obesity. In Taste and Development. The Genesis of Sweet Preference, pp. 309-329 [J. M. Weiffenbach, editor]. Bethesda, Maryland: National Institutes of Health.

Grinker, J., Hirsch, J. \& Smith, D. V. (1972). Taste sensitivity and susceptibility to external influence in obese and normal weight subjects. Journal of Personality and Social Psychology 22, 320-325.

Grinker, J. A., Price, J. M. \& Greenwood, M. R. C. (1976). Studies in taste in childhood obesity. In Hunger: Basic Mechanisms and Clinical Implications, pp. 441-457 [D. Novin, W. Wyrwicka and G. A. Bray, editors]. New York: Raven Press.

Guilford, J. P. (1954). Psychometric Methods. New York: McGraw-Hill.

Harris, G. \& Booth, D. A. (1985). Sodium preference in food and previous dietary experience in 6-month-old infants. IRCS Medical Science 13, 1177-1178.

Henkin, R. I. (1974). Salt taste in patients with essential hypertension and with hypertension due to primary hyperaldosteronism. Journal of Chronic Diseases 27, 235-244.

Henkin, R. I. (1980). Salt taste and salt preference in normal and hypertensive rats and humans. In Biological and Behavioral Aspects of Salt Intake, pp. 367-396 [M. R. Kare, M. J. Fregly and R. A. Bernard, editors]. New York: Academic Press.

Henkin, R. I. (1984). Zinc in taste function: a critical review. Biological and Trace Elements Research 6, 263-280.

Henkin, R. I., Gill, J. R. \& Bartter, F. C. (1963). Studies of taste thresholds in normal man and in patients with adrenal cortical insufficiency: the role of adrenal cortical steroids and of serum sodium concentration. Journal of Clinical Investigation 42, 727-735.

Ishida, H., Takahashi, H., Suzuki, H., Hongo, T., Suzuki, T., Shidoji, Y. \& Yoon, K. H. (1985). Interrelationship of some selected nutritional parameters relevant to taste for salt in a group of college-aged women. Journal of Nutritional Science and Vitaminology 31, 585-598. 
Johnson, W. G., Keane, T. M., Bonar, J. R. \& Downey, C. (1979). Hedonic ratings of sucrose solutions : effects of body weight, weight loss and dietary restriction. Addictive Behaviors 4, 231-236.

Krondl, M. \& Lau, D. (1982). Social determinants in human food selection. In The Psychobiology of Human Food Selection, pp. 139-151 [L. M. Barker, editor]. Chichester: Ellis Horwood.

Lauer, R. M., Filer, L. J., Reiter, M. A. \& Clarke, W. R. (1976). Blood pressure, salt preference, salt threshold, and relative weight. American Journal of Diseases of Children 130, 493-497.

McBride, R. L. (1983). A JND-scale/category-scale convergence in taste. Perception and Psychophysics 34. 77-83.

McNutt, K. W., Powers, M. E. \& Sloan, A. E. (1986). Food colors, flavors, and safety: a consumer viewpoint. Food Technology 40 (1), $72-78$.

Malcolm, R., O’Neil, P. M., Hirsch, A. A., Currey, H. S. \& Moskowitz, G. (1980). Taste hedonics and thresholds in obesity. International Journal of Obesity 4, 203-212.

Maller, O., Cardello, A., Sweeney, J. \& Shapiro, D. (1982). Psychophysical and cognitive correlates of discretionary usage of table salt and sugar by humans. In Determination of Behaviour by Chemical Stimuli, pp. 205-218 [J. E. Steiner and J. R. Ganchrow, editors]. London: IRL Press.

Marya, R. K., Sood, S., Sood, A. K. \& Maini, B. K. (1985). Effects of hyponatraemia on taste threshold for salt in hypertensive subjects. Indian Heart Journal 37, 170-171.

Mattes, R. D. (1984). Salt taste and hypertension: a critical review of the literature. Journal of Chronic Diseases 37, 195-208.

Mattes, R. D. (1985). Gustation as a determinant of ingestion: methodological issues. American Journal of Clinical Nutrition 41, 672-683.

Mattes, R. D. (1986). Effects of health disorders and poor nutritional status on gustatory function. Journal of Sensory Studies 1, 275-290.

Mattes, R. D. (1987). Assessing salt taste preference and its relationship with dietary sodium intake in humans. In Food Acceptance and Nutrition, pp. 129-142 [J. Solms, D. A. Booth, R. M. Pangborn and O. Raunhardt, editors]. London: Academic Press.

Mattes, R. D., Heller, A. D. \& Rivlin, R. S. (1986). Abnormalities in suprathreshold taste function in early hyperthyroidism in humans. In Clinical Measurement of Taste and Smell, pp. 467-486 [H. L. Meiselman and R. S. Rivlin, editors]. New York: Macmillan.

Mattes, R. D., Kumanyika, S. K. \& Halpern, B. P. (1983). Salt taste responsiveness and preference among normotensive, prehypertensive and hypertensive adults. Chemical Senses 8, 27-40.

Mattes, R. D. \& Mela, D. J. (1986). Relationships between and among selected measures of sweet-taste preference and dietary intake. Chemical Senses 11, 523-539.

Mattes-Kulig, D. A. \& Henkin, R. I. (1985). Energy and nutrient consumption of patients with dysgeusia. Journal of the American Dietetic Association 85, 822-826.

Merzon, K. A., Logoveeva, T. N., Shchetinen, L. N. \& Priklonskii, I. V. (1981). Excessive table salt consumption in arterial hypertension: habit or need. Kardiologiya 21, 96-97.

Midkiff, E. E. \& Bernstein, I. L. (1985). Targets of learned food aversions in humans. Physiology and Behavior 34, 839.

Mossman, K. L. \& Henkin, R. I. (1978). Radiation-induced changes in taste acuity in cancer patients. International Journal of Radiation, Oncology and Biological Physics 4, 663-670.

Odeigah, P. G. C. \& Obieze, A. C. (1986). Differences in sodium chloride taste sensitivity in a rural and an urban population in Nigeria: implications for the incidence of hypertension. East African Medical Journal 63, 236-243.

Pangborn, R. M., Bos, K. E. O. \& Stern, J. S. (1985). Dietary fat intake and taste responses to fat in milk by under-, normal, and overweight women. Appetite 6, 25-40.

Pangborn, R. M. \& Giovanni, M. E. (1984). Dietary intake of sweet foods and of dairy fats and resultant gustatory responses to sugar in lemonade and to fat in milk. Appetite 5, 317-327.

Pangborn, R. M. \& Pecore, S. D. (1982). Taste perception of sodium chloride in relation to dietary intake of salt. American Journal of Clinical Nutrition 35, 510-520.

Pangborn, R. M. \& Simone, M. (1958). Body size and sweetness preference. Journal of the American Dietetic Association 34, 924-928.

Peryam, D. R. \& Pilgrim, F. J. (1957). Hedonic scale method of measuring food preferences. Food Technology 11, Suppl., 9-14.

Peryam, D. R., Polemis, B. W., Kamen, J. M., Eindhoven, J. \& Pilgrim, F. J. (1960). Food Preferences of Men in the US Armed Forces. Chicago: Quartermaster Food and Container Institute.

Pilgrim, F. J. (1957). The components of food acceptance and their measurement. American Journal of Clinical Nutrition 5, 171-175.

Randall, E. \& Sanjur, D. (1981). Food preferences - their conceptualization and relationship to consumption. Ecology of Food and Nutrition 11, 151-161.

Richter, C. P. (1936). Increased salt appetite in adrenalectomized rats. American Journal of Physiology 115 , 155-161.

Richter, C. P. (1939). Salt taste thresholds of normal and adrenalectomized rats. Endocrinology 24, 367-371. 
Richter, C. P. (1956). Salt appetite in mammals: its dependence on instinct and metabolism. In L'Instinct dans le Comportement des Animaux et de L'Homme, pp. 577-629 [M. Autuori, editor]. Paris: Masson.

Rodin, J. (1975). Effects of obesity and set point on taste responsiveness and intake in humans. Journal of Comparative and Physiological Psychology 89, 1003-1009.

Rodin, J., Moskowitz, H. R. \& Bray, G. A. (1976). Relationship between obesity, weight loss and taste responsiveness. Physiology and Behavior 17, 391-397.

Rolls, B. J., Rolls, E. T. \& Rowe, E. A. (1982). The influence of variety on human food selection and intake. In The Psychobiology of Human Food Selection, pp. 101-122 [L. M. Barker, editor]. Chichester: Ellis Horwood.

Rozin, P. (1982). Human food selection: the interaction of biology, culture, and individual experience. In The Psychobiology of Human Food Selection, pp. 225-254 [L. M. Barker, editor]. Chichester: Ellis Horwood.

Rozin, P. \& Schiller, D. (1980). The nature and acquisition of a preference for chili pepper by humans. Motivation and Emotion 4, 77-101.

Sanchez-Castillo, C. P., Warrender, S., Whitehead, T. \& James, W. P. T. (1984). Epidemiological assessment of sodium sources in the diet by the use of the lithium-marker technique. Proceedings of the Nutrition Society 43, 153A.

Schafer, R. B. (1978). Factors affecting food behavior and the quality of husbands' and wives' diets. Journal of the American Dietetic Association 72, 138-143.

Schechter, P. J., Horwitz, D. \& Henkin, R. I. (1973). Sodium chloride preference in essential hypertension. Journal of the American Medical Association 225, 1311-1315.

Schiffman, S. S. (1983a). Taste and smell in disease. Part 1. New England Journal of Medicine 308, $1275-1279$.

Schiffman, S. S. (1983b). Taste and smell in disease. Part 2. New England Journal of Medicine 308, $1337-1343$.

Schutz, H. G, Rucker, M. H. \& Russell, G. F. (1975). Food and food-use classification systems. Food Technology 29, $50-64$.

Settle, R. G. (1986). Diabetes mellitus and the chemical senses. In Clinical Measurement of Taste and Smell, pp. 487-513 [H. L. Meiselman and R. S. Rivlin, editors]. New York: Macmillan.

Shepherd, R. (1985). Dietary salt intake. Nutrition and Food Science 96, 10-11.

Shepherd, R. (1987). The effects of nutritional beliefs and values on food acceptance. In Food Acceptance and Nutrition, pp. 387-402 [J. Solms, D. A. Booth, R. M. Pangborn and O. Raunhardt, editors]. London : Academic Press.

Shepherd, R. (1988). Consumer attitudes and food acceptance. In Food Acceptability [D. M. H. Thomson, editor]. London: Elsevier Applied Science. (In the Press.)

Shepherd, R. \& Farleigh, C. A. (1986a). Attitudes and personality related to salt intake. Appetite 7, 343-354.

Shepherd, R. \& Farleigh, C. A. (1986 b). Preferences, attitudes and personality as determinants of salt intake. Human Nutrition: Applied Nutrition 40A, 195-208.

Shepherd, R. \& Farleigh, C. A. (1987). Salt intake assessment by questionnaire and urinary sodium excretion. Nutrition Research 7, 557-568.

Shepherd, R., Farleigh, C. A. \& Land, D. G. (1984a). Preference and sensitivity to salt taste as determinants of salt-intake. Appetite 5, 187-197.

Shepherd, R., Farleigh, C. A. \& Land,D. G. (1984b). The relationship between salt intake and preferences for different salt levels in soup. Appetite 5, 281-290.

Shepherd, R., Farleigh, C. A. \& Land, D. G. (1985). Estimation of salt intake by questionnaire. Appetite 6, $219-233$.

Shepherd, R., Farleigh, C. A. \& Wharf, S. G. (1987). Preferences for salt in different foods and their relationship to availability of sodium. Human Nutrition: Food Sciences and Nutrition 41F, 173-181.

Simoons, F. J. (1982). Geography and genetics as factors in the psychobiology of human food selection. In The Psychobiology of Human Food Selection, pp. 205-224 [L. M. Barker, editor]. Chichester: Ellis Horwood

Simpson, F. O. (1979). Salt and hypertension: a sceptical review of the evidence. Clinical Science 57, $463 \mathrm{~S}-480 \mathrm{~S}$.

Solms, J. \& Hall, R. L. (1981). Criteria of Food Acceptance: How Man Chooses What He Eats, Zurich: Forster.

Stinebaugh, B. J., Vasquez, M. I. \& Schloeder, F. X. (1975). Taste thresholds for salt in fasting patients. American Journal of Clinical Nutrition 28, 814-817.

Thompson, D. A., Moskowitz, H. R. \& Campbell, R. G. (1976). Effects of body weight and food intake on pleasantness ratings for a sweet stimulus. Journal of Applied Psychology 41, 77-83.

Tobian, L. (1979). The relationship of salt to hypertension. American Journal of Clinical Nutrition 32, 2739-2748.

Tuorila, H. (1987). Selection of milks with varying fat contents and related overall liking, attitudes, norms and intentions. Appetite 8, 1-14.

Williams, D. R. R. \& Bingham, S. A. (1986). Sodium and potassium intakes in a representative population sample: Estimation from $24 \mathrm{~h}$ urine collections known to be complete in a Cambridgeshire village. British Journal of Nutrition 55, 13-22.

Witherly, S. A., Pangborn, R. M. \& Stern, J. S. (1980). Gustatory responses and eating duration of obese and lean adults. Appetite 1, 53-63. 
Wotman, S., Mandel, I. D., Thompson, R. H. \& Laragh, J. H. (1967). Salivary electrolytes and salt taste thresholds in hypertension. Journal of Chronic Diseases 20, 833-840.

Yensen, R. (1959). Some factors affecting taste sensitivity in man. II. Depletion of body salt. Quarterly Journal of Experimental Psychology 11, 230-238. 